\title{
Spatial heterogeneity in snow water equivalent induced by forest canopy in a mixed beech-fir stand in the Pyrenees
}

\author{
J. IGNACIO LÓPEZ-MORENO, ${ }^{1,2}$ J. LATRON ${ }^{3}$ \\ ${ }^{1}$ Instituto Pirenaico de Ecología, Consejo Superior de Investigaciones Cientificas, Campus de Aula Dei, \\ PO Box 202, ES-50080 Zaragoza, Spain \\ E-mail: nlopez@ipe.csic.es \\ ${ }^{2}$ Climatic Change and Climate Impacts Group, University of Geneva, Batelle-D.7, Chemin de Drize, \\ $\mathrm{CH}-1227$ Carouge (Geneva), Switzerland \\ ${ }^{3}$ Soil Science Unit, University of Girona, Campus de Montilivi, ES-17071 Girona, Spain
}

\begin{abstract}
This paper analyzes the effect of forest canopy on snow water equivalent during two consecutive snow seasons in a mixed beech-fir stand in the Pyrenees. The results confirm that the forest canopy is a dominant influence on snowpack distribution during the accumulation and melting periods. In general, a noticeable decrease in snow water equivalent and an increase in variability among observations are detected with increasing density of the forest canopy. The influence of the forest canopy on melting rates is complex and highly dependent on the dominant climatic conditions. Similar conclusions are reached for both of the snow seasons for which measurements are available, but several differences are also recorded. This study highlights the important influence of climatic conditions observed during the snow season on the relationship between stand characteristics and snowpack dynamics.
\end{abstract}

\section{INTRODUCTION}

The presence of a seasonal snowpack is one of the main characteristics of mid- and high-latitude mountains. The length of the snow-cover season and the thickness of the snowpack control many environmental processes, mainly those related to the phenology of plants and animals, soil properties and the fluvial regimes of snow-fed rivers (LópezMoreno and García-Ruiz, 2004).

In addition to topography which controls the thermal regime, incoming radiation and the redistribution of snow by avalanches and snowdrift processes, the forest canopy is a key element in explaining the heterogeneity of snowpack across the landscape, even across very short distances. Many studies have recognized and quantified the effect of forest and canopy density on snow accumulation and melting dynamics (i.e. Hedstrom and Pomeroy, 1998; Koivusalo and Kokkonen, 2002; Pomeroy and others, 2002; Lundberg and others, 2004; Mellander and others, 2005; Winkler and Moore, 2006; López-Moreno and Latron, 2008). Previous results vary noticeably according to the geographic location and stand characteristics, but general agreement exists about the importance of the forest canopy in reducing the maximum snow water equivalent (SWE) as a consequence of the interception of snow and further sublimation, and in leading to increased spatial variability in snowpack relative to open sites (Hedstrom and Pomeroy, 1998; Pomeroy and others, 2002; Lundberg and others, 2004; Mellander and others, 2005).

Results obtained concerning the role of forest during melting periods are more contradictory, as under any given set of conditions trees are a source of longwave radiation, thereby enhancing the melting rates in surrounding areas (Sicart and others, 2004). Trees also shield the snowpack from incoming solar radiation, resulting in lower melting rates than those recorded at open sites (Marks and others, 1998; Talbot and others, 2006).
Openings within forest stands usually present the most favourable conditions for accumulating a thick snowpack over a longer period, as such sites are unaffected by interception by needles and branches. Moreover, melting rates are relatively low at such sites because the amount of longwave radiation received from nearby trees is negligible, yet most openings benefit from the shadowing effect of the surrounding trees (Bernier and Swanson, 1993; Pomeroy and others, 2002).

The results of previous studies suggest that the effect of forest canopy on snowpack depends on climatic conditions during the observation period (Hedstrom and Pomeroy, 1998; Marks and others, 1998; Murray and Buttle, 2003; Mellander and others, 2005). This implies the potential existence of high interannual variability in the relationships between forest canopy and snow accumulation and melting processes (López-Moreno and Stähli, 2008). This is an important issue, as the global climate is expected to change in the coming decades, and the situation for a given area may vary under the changed climatic conditions of the future; however, the fact that few investigations have been carried out regularly over multiple years makes it difficult to obtain a deep understanding of the links between climatic conditions and the role of forest cover on snowpack. This is particularly true for Mediterranean mountain areas, where no experimental studies have considered snow-cover dynamics in forested areas.

To address this lack of data, we designed an experiment based on regular surveys during the full snow seasons of two consecutive years within a mixed beech-fir stand in the Pyrenees at $1550 \mathrm{~m}$ a.s.l. The results obtained during the first measurement season (2004/05; see López-Moreno and Latron, 2008) revealed a very strong correlation between forest density derived from hemispherical photographs and SWE, with differences in SWE in excess of $50 \%$ when the densest canopies were compared with openings. Moreover, melting began earlier in areas with relatively dense canopy. 

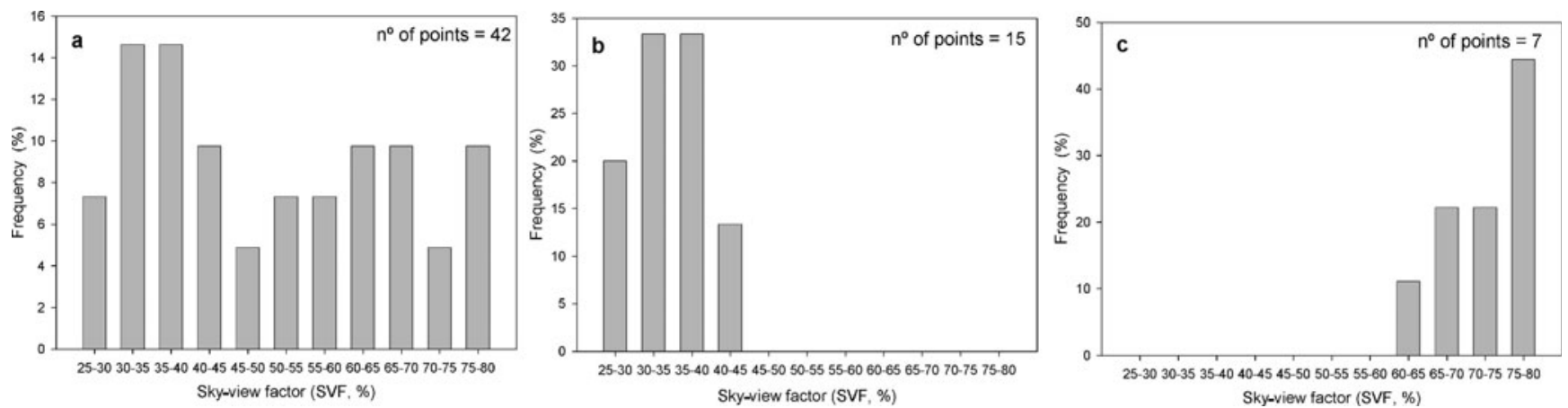

Fig. 1. Frequency distribution of the SVF of the measurement points: (a) all points; (b) points under densest canopy; and (c) points at openings.

In the present paper, with a second season of measurements available (2005/06), we assess whether the earlier findings are maintained in a snow season with contrasting climatic characteristics. Moreover, using all of the 32 available surveys, we analyze the different patterns of variability in SWE between the consecutive surveys and examine changes in the degree of spatial heterogeneity of snowpack throughout the two analyzed snow seasons.

\section{STUDY SITE}

The studied stand is located in a flat area at the bottom of a north-facing slope at $1550 \mathrm{ma.s.l.}$, close to the divide between the Aragón (Spain) and Aspe (France) valleys. Average annual temperature in the area is around $5{ }^{\circ} \mathrm{C}$, and precipitation is close to $1815 \mathrm{~mm} \mathrm{a}^{-1}$, with around $30 \%$ falling as snow. During the 2 years of research, snowpack remained over the ground from mid-December to the middle to end of April, a period which recorded an average precipitation of $606 \mathrm{~mm}$ (33.4\% of total annual precipitation) and a mean temperature of $-0.23^{\circ} \mathrm{C}$.

The study site was selected based on the following criteria: its flat and homogeneous topography; the lack of shrub cover; and high variability in the density of the forest canopy, which, when quantified using the sky-view factor (SVF), ranged from $25.1 \%$ to $79.6 \%$ for a zenith angle up to $55^{\circ}$ (see section 3 and López-Moreno and Latron, 2008). These conditions enabled us to isolate the effect of stand characteristics on snow-cover dynamics.

The stand is composed of mature fir and beech trees (mean height of approximately $20 \mathrm{~m}$ and, in most cases, a diameter at breast height $\mathrm{DBH}>60 \mathrm{~cm}$ ) over an area close to 3 ha $\left(0.03 \mathrm{~km}^{2}\right)$; the stand has remained unaffected by human activity over recent decades. Several openings occur within the stand, with the radii of the openings being less than twice the tree height $(<2 H)$. Except for the openings, the density of the canopy is high (SVF $=25.2-50.3 \%$ ). Such density is more a consequence of the maturity of the individual trees, with large branches and a well-developed vertical structure, than of the high density of trees, which present a mean distance between the trunks within the stand of $\sim 15-20 \mathrm{~m}$. The existence of sparse beech trees within the stand is the main reason for the variability of SVF, since the vertical and horizontal structure of fir trees is homogeneous.

\section{DATA AND METHODS}

Six transects were established across the stand to capture the maximum heterogeneity in forest canopy characteristics, including existing openings $(<2 H)$. Snow-depth and -density data were obtained at 42 points spaced at regular intervals ( $2.5 \mathrm{~m}$ in areas beneath canopy cover and $5 \mathrm{~m}$ in openings) along each transect. Snow depth was measured using a steel probe, while density was estimated by weighing a known volume of snow sampled using a PVC tube of $5 \mathrm{~cm}$ diameter. Measurements of snow depth and density were systematically replicated (four measurements at each point) to negate potential irregularities in the terrain and any mistakes made in the sampling of snow cores when estimating density. Thus, the final depth value was derived by averaging the four measurements, while rejecting those measurements with a bias greater than $25 \%$ of the other three measurements.

The product of snow depth and density yields the SWE $\left(\mathrm{kg} \mathrm{m}^{-2}\right)$. A measurement point located in an open site outside the stand $(>5 H)$ was also sampled to record the evolution of snow in an area free of the potential effect of the forest canopy. Surveys were carried out every 1-2 weeks depending upon weather conditions and road access. Measurements were carried out from 11 November 2004 to 30 April 2005 in the first year and from 14 December 2005 to 19 April 2006 in the second. In both cases, the end of the survey corresponded to the time at which the snow had almost totally melted.

From 1 January 2005 onwards, air temperature was measured using a HOBO temperature sensor connected to an $\mathrm{H} 8$ data logger (http://onsetcomp.com) installed in an opening within the stand. Precipitation data were obtained from a meteorological station located $<10 \mathrm{~km}$ from the stand; the station and the stand experience similar exposure to air masses, but the stand is located at the higher elevation of $2060 \mathrm{~m}$. Therefore, bearing in mind the potential differences in precipitation recorded at the two sites, the available data were used only to characterize the occurrence of dry and wet spells during the study periods.

SVF obtained from hemispherical digital photographs with a zenith angle up to $55^{\circ}$ was used to determine the density of the forest canopy (Hellström, 2000). Additional detailed information on the experimental design and its application can be found in López-Moreno and Latron (2007). The present work focuses mainly on a comparison between measurements taken in areas located below the densest canopies (mean SVF of 34\%) and those taken in openings (mean SVF of $69 \%$ ). Figure 1 shows the histograms of frequency of the SVF of the measurement points. Figure 1a shows the frequency of different ranges in which the SVFs of the 42 points of measurement are distributed. It confirms that the sampling points regularly cover a wide range of canopy density $(S V F=25.1-79.6 \%)$, with a mean value of $50.3 \%$. 


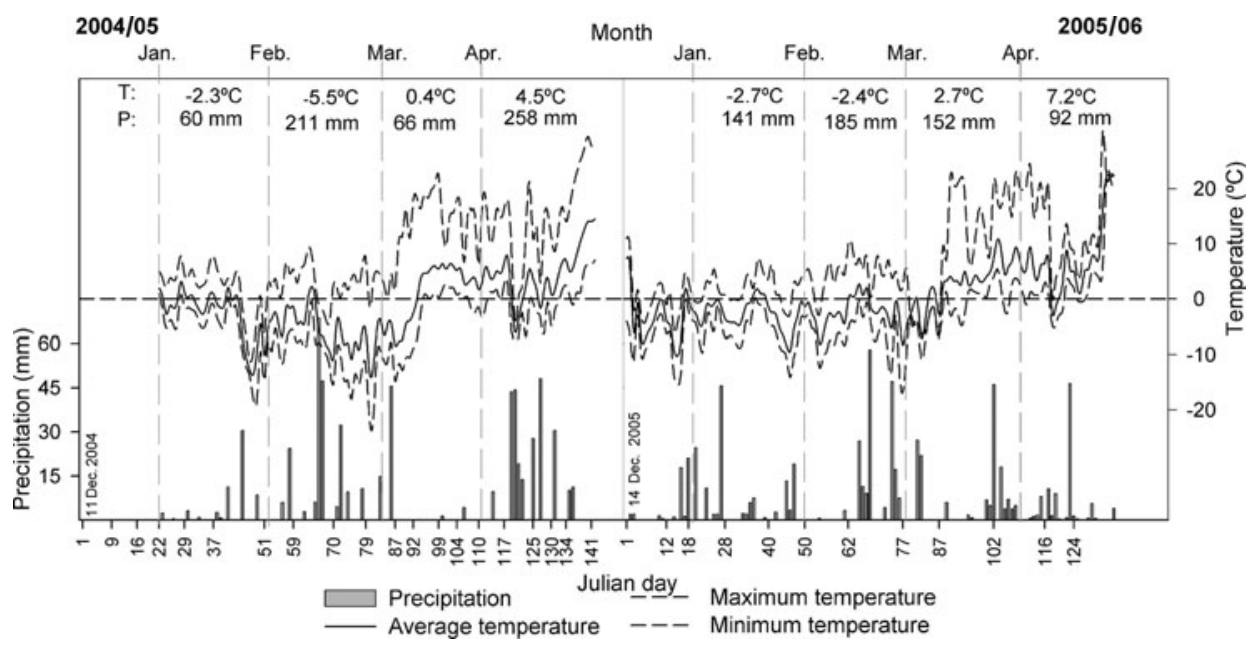

Fig. 2. Evolution of air temperature and precipitation during the two analyzed years.

Figure $1 \mathrm{~b}$ and $\mathrm{c}$ show the frequency of samples in different ranges of SVF of the 15 measurement points considered as the densest canopies (SVF $=25.1-43.4 \%$; mean value 34\%) and the 9 points representative of the openings (SVF $=61.2-$ $79.6 \%$; mean value $72.8 \%$ ), respectively.

\section{RESULTS}

Figure 2 shows the temporal evolution of air temperature and precipitation over the two analyzed years. Table 1 provides the monthly average, maximum and minimum temperature and precipitation. Data of December 2005 correspond to the period following 14 December, when the first snow survey was done. The 2004/05 snow season was characterized by cold temperatures in January and February (average values of $-2.3^{\circ} \mathrm{C}$ and $-5.5^{\circ} \mathrm{C}$, respectively), temperatures of around $0^{\circ} \mathrm{C}$ in March, and a clear increase in temperature by the end of March and the beginning of April (average temperature of $4.5^{\circ} \mathrm{C}$ ). January and March were dry months (precipitation of 60 and $66 \mathrm{~mm}$, respectively), whereas February recorded $211 \mathrm{~mm}$ of precipitation; most of the precipitation fell during temperatures below $0^{\circ} \mathrm{C}$. A total of $258 \mathrm{~mm}$ fell in April, with a general coincidence between wet events and relatively cold spells characterized by temperatures close to the snow-rain threshold $\left(\sim 0-1{ }^{\circ} \mathrm{C}\right)$.

The 2005/06 snow season was generally warmer than that of the previous year, especially during March and April when the average temperatures were $2.7^{\circ} \mathrm{C}$ and $7.2^{\circ} \mathrm{C}$, respectively. January and February recorded 141 and $185 \mathrm{~mm}$ of precipitation, respectively, most of which fell at temperatures below the snow-rain threshold. March and April recorded 152 and $92 \mathrm{~mm}$ of precipitation, respectively. The temperatures recorded during the days with precipitation suggest that much of this precipitation fell as rain.

Figure 3 shows the response of snowpack to the climatic conditions described above, highlighting the effect of forest on snow accumulation and melting processes. Figure $3 \mathrm{a}$ shows the evolution of mean SWE measured within openings and areas of dense canopy, and the site unaffected by forest. In terms of climatic conditions, the evolution of mean SWE for the stand during the 2004/05 season was characterized by a slow increase during January, which was a cold but relatively dry period. The maximum SWE for the snow season was attained at the beginning of March after a prolonged cold and wet period. After a short period characterized by a slight decrease in SWE (days 87-99), melting occurred at high rates (days 99-117 and 130-141), interrupted only by 2 weeks of accumulation at the end of March and the beginning of April.

The SWE data for areas of dense forest and open areas show interesting differences in terms of magnitude of the snowpack and response to particular climatic conditions. Thus, over the entire season, SWE was noticeably lower (61\% on average) in areas with dense canopy than in open areas. At the time that maximum SWE (day 109) was attained in the openings $\left(555.5 \mathrm{~kg} \mathrm{~m}^{-2}\right)$, areas below a dense canopy had accumulated only $58 \%$ of that amount (day 97; $326.2 \mathrm{~kg} \mathrm{~m}^{-2}$ ). These differences were even more pronounced during the melt period (see day 117 in Fig. 2a), as melting rates were generally higher below the canopy (in four of the seven recorded melting periods). Moreover, a time lag of almost 2 weeks was observed between the two situations (openings and areas below a dense canopy) for the beginning of the melt period: the melt period started from day 97 below dense canopy, whereas accumulation continued until day 109 in the openings.

At the end of the season (day 127; mid-April), snow had practically disappeared below the canopy (SWE $=$ $46.6 \mathrm{~kg} \mathrm{~m}^{-2}$ ), but remained (SWE $=319 \mathrm{~kg} \mathrm{~m}^{-2}$ ) in the openings, where it would rapidly thaw over the following days. Similarly, in the snow survey carried out on day 144 , only

Table 1. Monthly average $\left(T_{\text {avg }}\right)$, maximum $\left(T_{\max }\right)$ and minimum $\left(T_{\min }\right)$ temperature and precipitation recorded at the study site during the 2004/05 and 2005/06 snow seasons

\begin{tabular}{|c|c|c|c|c|c|c|c|c|}
\hline & \multicolumn{4}{|c|}{ 2004/05 } & \multicolumn{4}{|c|}{$2005 / 06$} \\
\hline & $\begin{array}{l}T_{\text {avg }} \\
{ }^{\circ} \mathrm{C}\end{array}$ & $\begin{array}{c}T_{\max } \\
{ }^{\circ} \mathrm{C}\end{array}$ & $\begin{array}{c}T_{\min } \\
{ }^{\circ} \mathrm{C}\end{array}$ & $\begin{array}{c}\text { Precip. } \\
\text { mm }\end{array}$ & $\begin{array}{l}T_{\text {avg }} \\
{ }^{\circ} \mathrm{C}\end{array}$ & $\begin{array}{l}T_{\max } \\
{ }^{\circ} \mathrm{C}\end{array}$ & $\begin{array}{c}T_{\min } \\
{ }^{\circ} \mathrm{C}\end{array}$ & $\begin{array}{c}\text { Precip. } \\
\text { mm }\end{array}$ \\
\hline December & - & - & - & - & -3.2 & 1.6 & -7.1 & 46.6 \\
\hline January & -2.3 & 2.4 & -5.5 & 59.9 & -2.7 & 1.8 & -5.8 & 141.4 \\
\hline February & -5.5 & 2.8 & -10.3 & 211.9 & -2.4 & 4.6 & -6.7 & 184.8 \\
\hline March & 0.4 & 12.7 & -4.7 & 65.7 & 2.7 & 9.4 & -3.4 & 152.6 \\
\hline April & 4.5 & 14.6 & -0.6 & 257.7 & 7.2 & 14.3 & 1 & 92 \\
\hline
\end{tabular}




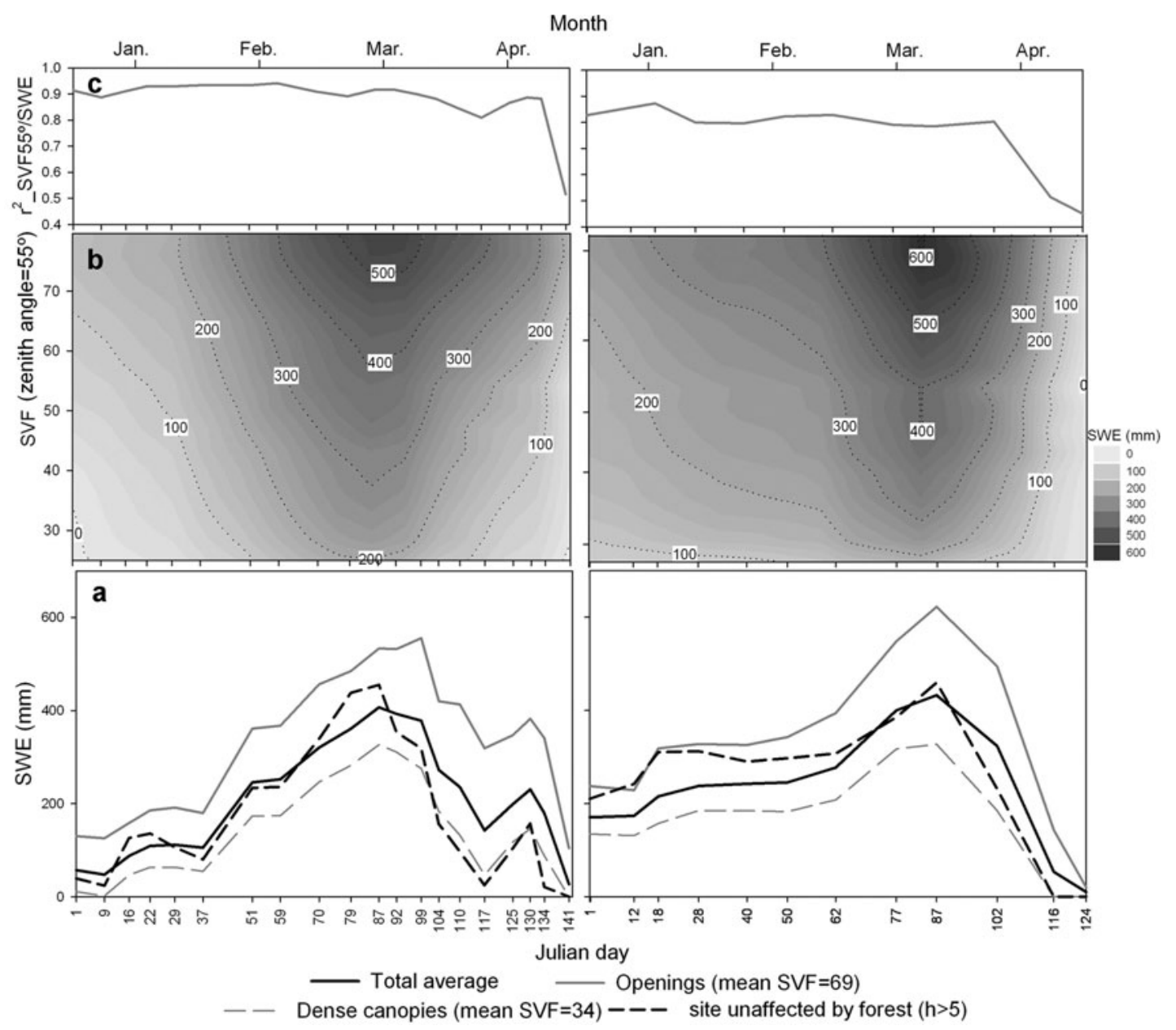

Fig. 3. (a) Evolution of the mean SWE measured at the openings, the dense canopy areas and the site unaffected by forest throughout the snow seasons. (b) Relationship between the SVF (determined with a zenith angle of $55^{\circ}$ ), which is indicative of the density of the forest canopy, and the mean SWE measured at the 42 measurement points within the stand. (c) Evolution of the correlation coefficient between SVF and mean SWE. The $x$ axes show the number of Julian days after 1 December when snow surveys were carried out.

$88.4 \mathrm{~kg} \mathrm{~m}^{-2}$ of SWE remained below the densest canopy, while an average of $340.4 \mathrm{~kg} \mathrm{~m}^{-2}$ was measured in the openings. Snow measurements taken at the site unaffected by forest show that accumulation was lower than that observed in the openings (69\% on average), with a maximum SWE of $455 \mathrm{~kg} \mathrm{~m}^{-2}, 81 \%$ of that recorded in the openings and $28 \%$ more than accumulated under the densest canopies. However, melting rates were much higher than within the stand, exceeding the rate of thawing observed below the dense canopy (see days 97-127 in Fig. 2a).

During the 2005/06 snow season, maximum SWE was attained on 11 March (day 87) after a prolonged cold and wet period during January and February. Later in the season, snowpack completely melted in 37 days, implying a much higher melt rate than during the previous year, when snowpack melted in 49 days. The faster ablation of snowpack during the 2005/06 season reflects the effects of both the high temperatures and frequent rain events on the snowpack, as can be deduced from Figure 2. As in the previous year, clear differences were recorded between the amount of snow that accumulated under dense forest and that which accumulated in openings. On average, during the snow season, mean SWE under dense forest is $53 \%$ of that measured in openings. The mean maximum SWE (day 100) measured under the dense canopy, $326.9 \mathrm{~kg} \mathrm{~m}^{-2}$, represents only $52 \%$ of the $622.7 \mathrm{~kg} \mathrm{~m}^{-2}$ measured in the openings.
Differences became even more pronounced 2 weeks later (day 115) during the middle of the melting period (SWE accumulated under dense canopy was $63 \%$ less than in openings). During this year, no delay was observed in the beginning of the melt period in the openings, and the snow cover disappeared 8 days earlier below the forest canopy. As in 2004/05, snowpack at the site unaffected by the forest followed an intermediate evolution between that of the openings and dense canopies, with the maximum accumulation $\left(459 \mathrm{~kg} \mathrm{~m}^{-2}\right)$ being $73 \%$ of the amount accumulated in the openings and $40 \%$ higher than accumulated below dense canopies. Melting was more rapid in the open area than within the forest stand. Thus, at the open site and under the densest canopy, snowpack was completely melted by 9 April (day 129), whereas in the openings it remained $143 \mathrm{~kg} \mathrm{~m}^{-2}$ of SWE.

Figure $3 \mathrm{~b}$ shows variations in SWE measured at each point during the 20 and 14 surveys carried out during the 2004/05 and 2005/06 snow seasons respectively, along with the corresponding SVF (zenith angle of $55^{\circ}$ ). It is seen that the differences in SWE between openings and areas with dense canopy were clearly related to the density of the canopy, with a clear correlation observed throughout the snow season between SVF measured at each point and SWE (see Fig. 3c); however, correlations were generally stronger during the 2004/05 snow season ( $r$ values $>0.90$ for most of 

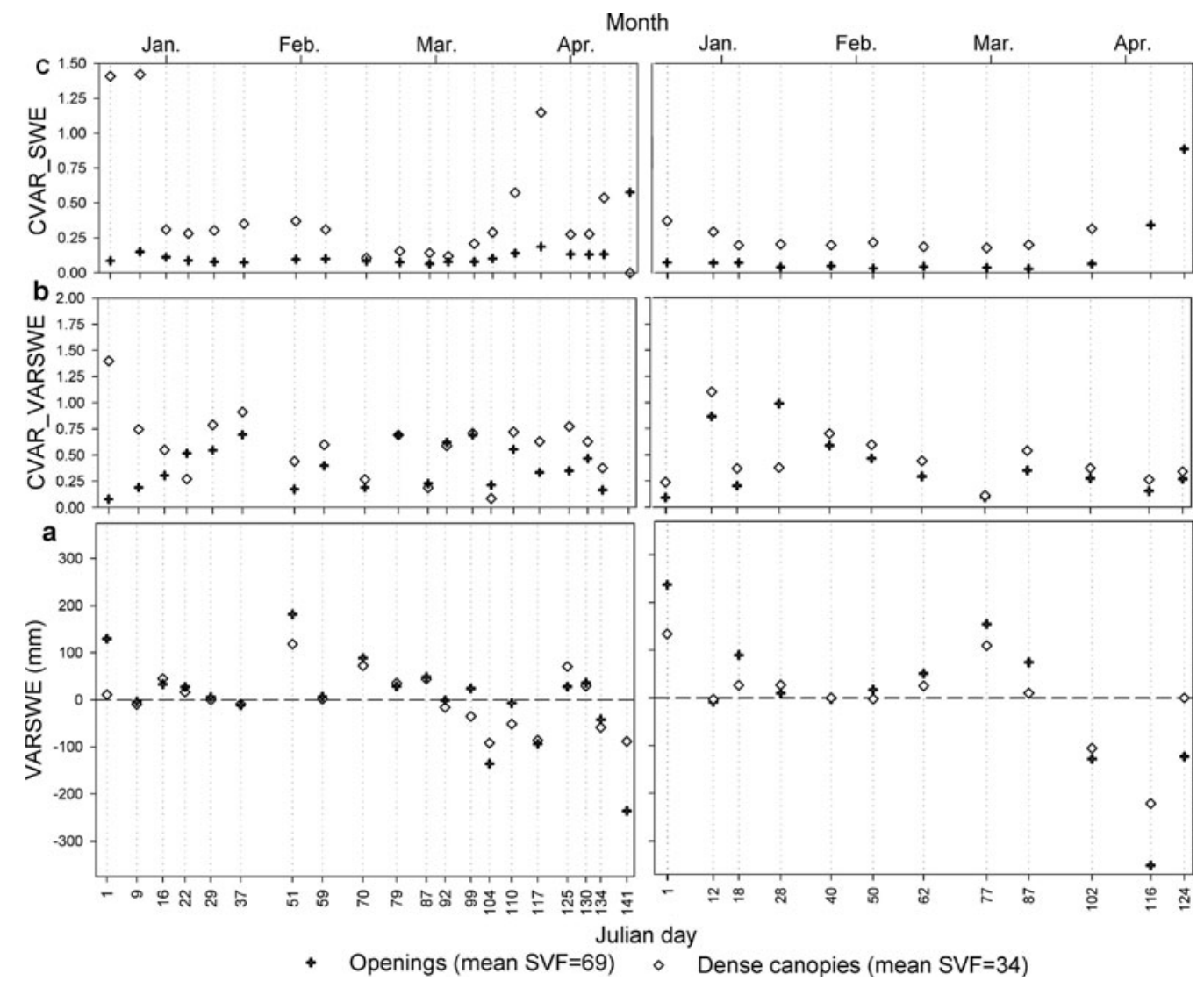

Fig. 4. (a) Mean difference in SWE measured in openings and areas below dense canopies between two consecutive snow surveys. (b) CV of the differences in mean SWE throughout the snow seasons. (c) CV in the mean SWE throughout the snow seasons.

the period) than during the 2005/06 season ( $r$ values around 0.8 ). The existence of points devoid of snow cover at the end of both seasons provides a partial explanation of the sharp fall in $r$ values recorded in April.

Figure 4 shows the mean difference in SWE between two successive surveys in openings and in areas below a dense canopy (Fig. 4a), as well as the corresponding coefficient of variation (CV; Fig. 4b) and the CV of SWE observed in each survey (Fig. 4c).

Figure 4a shows that large differences in SWE between openings and areas below dense canopy during the accumulation period (see Fig. 3a) were mainly due to the occurrence of several particular snowfall events at times when the forest canopy was especially effective in intercepting snow (days 11, 61 and 109 for 2004/05, and 14, 31, 90 and 100 for 2005/06); however, for many periods the snow accumulation was similar across the entire stand, as indicated by similar trends recorded by openings and forest sites (days 19, 26, 32, 89 and 97 for 2004/05, and 41 and 75 for 2005/06).

During both snow seasons, the greatest differences in snow accumulation occurred during the first snowfall events and after long dry spells (days 47-61 in 2004/05, and days 25-31 in 2005/06). Clear differences also arose during periods of frequent snowfall events when temperatures occasionally exceeded $0^{\circ} \mathrm{C}$, as during days $90-100$ of the 2005/06 season when $46 \mathrm{~mm}$ of precipitation fell, with temperatures below $0^{\circ} \mathrm{C}$, after a warm spell when temperatures exceeded $20^{\circ} \mathrm{C}$. Periods of similar accumulation in both openings and areas below dense forest were observed mainly after prolonged accumulation periods (successive snowfall events) and with persistent cold temperatures, as occurred over days 69-80 during the 2004/05 season (58 $\mathrm{mm}$ of precipitation during six consecutive days and temperatures always below $0^{\circ} \mathrm{C}$ ). Figure 4 a also shows that the melting rate in openings (leading to negative variations in SWE) sometimes exceeded that observed below a dense canopy (days 114 and 127 for 2004/05, and 115 for 2005/ 06); in several cases, though, the opposite pattern was observed (days 109 and 120 for 2004/05).

No clear relationship was found between the situation with the highest rate of snowmelt and the dominant climatic conditions. Nevertheless, melting below the dense canopy was faster than that in openings when temperatures were markedly above $0^{\circ} \mathrm{C}$ (i.e. the periods 97-102, 102-109 and 114-120 days during the 2004/05 season); the opposite was observed during periods of positive temperatures close to $0^{\circ} \mathrm{C}$ (e.g. 109-114 days in 2004/05, when temperatures were generally positive but never exceeded $6^{\circ} \mathrm{C}$ ). The results for days 144-151 in 2004/05 and days 129-137 in 2005/06 were conditioned by a near-complete thaw of the snowpack below the dense forest canopy immediately before the end of the measuring period.

The CV associated with the mean variation of SWE between the consecutive surveys (Fig. 4b) shows that the degree of heterogeneity in snow changes between locations of similar characteristics was generally higher below dense forest (higher CV in 29 of the 32 snow surveys) than in openings; however, the difference between the CV determined for openings and that determined for dense forest varied significantly depending on the selected time interval. Thus, the main differences during accumulation periods 
were observed at the beginning of the snow seasons; after prolonged periods without snowfall, as during days 47-61 in 2004/05; and during periods of snow accumulation interrupting the 2004/05 melt season (days 127-135).

During the remainder of the accumulation periods, no large differences were observed between the two situations (the degree of heterogeneity in SWE variations was similar in openings and in areas below dense forest, with differences in CV lower than 0.3); however, higher variability was sometimes (days 32 and 41 in 2004/05 and 2005/06, respectively) observed in the openings, probably due to the effect of the redistribution of wind. During the melt period, the degree of heterogeneity in SWE variation was largely similar in openings and in areas below dense forest, although the slightly higher degree of variability recorded below the canopies occasionally increased significantly (e.g. the differences in $\mathrm{CV}$ of 0.3 and 0.42 recorded over days 127 and 135 in 2004/05).

Figure 4c shows the CV of SWE observed during each survey; these data reflect the accumulated effect of densely forested areas and openings on the variability of SWE distribution throughout the seasons shown in Figure 4b. The figure illustrates the low variability in SWE within openings throughout both seasons $(C V<0.14)$, except at the end of the melt period, when $\mathrm{CV}$ oscillated between 0.5 and 1.25. Below the densest canopies, SWE exhibited a higher variability between measurement points (mean $\mathrm{CV}=0.41$ ). During both seasons, the variability in SWE below the dense canopies decreased from the beginning of the season until the time when the maximum SWE was attained. The spatial variability in snowpack increased during the melt period.

\section{DISCUSSION}

The results derived from snowpack surveys carried out over two consecutive years highlight the large variability in SWE distribution induced by forest cover. Forest canopy affected both accumulation and melt processes and noticeably reduced the amount of maximum accumulated snow: the amount beneath dense canopies was $58 \%$ and $52 \%$ of that found in openings. This observed $42 \%$ and $48 \%$ reduction in maximum SWE during both years corresponds to the upper limit of the range (20-50\%) reported in previous studies undertaken in North America, the European Alps and Scandinavia (Pomeroy and Gray, 1995; Pomeroy and others, 2002; Lundberg and others, 2004; Niu and Yang, 2004; Stähli and Gustafsson, 2006).

In the present study, the amount of snow intercepted by branches and leaves was approximately linearly related to the density of the canopy, with correlations between SVF and SWE exceeding 0.9 for 2004/05 and 0.8 for 2005/06. The correlation was weaker in the second year from the time of the first accumulation event, probably as a consequence of the different characteristics of the first snowfall events (i.e. magnitude, intensity, thermal conditions, temperature of the canopy, etc.) in relation to 2004/05; this discrepancy was maintained for the rest of the season.

An analysis of changes in SWE between the consecutive surveys showed that the effect of the canopy on snow accumulation was highly variable. Although the sampling interval used and the unloading of snow intercepted by the canopy in a previous time slice may have implications in the interpretation of the analysis, results suggest that the changing differences in accumulation and melt processes in openings and under dense canopy depend mainly on the climatic conditions over the corresponding time interval. Thus, the interception capacity of the canopy was strongly limited after cold periods with frequent or heavy snowfalls. Such conditions were favourable to the permanence of the snow load over the canopy for long periods, reducing the capacity of the canopy to intercept significant fractions of new snowfall events, as already shown by Keller and Strobel (1982) and Mellander and others (2005). The opposite situation was observed for the first snowfall event of the season and after periods in which the conditions led to a canopy free of snow load (melting, sublimation, etc.). At these times, the canopy showed a greater capacity to intercept a large fraction of the incoming snow (Hedstrom and Pomeroy, 1998).

Our results confirm the complex role of forest during the melt season. During certain periods, snow melted faster in openings than below dense canopy; the opposite pattern was observed at other times. The contrasting behaviour of snowpack in the two environments might lead to different timings of maximum SWE, as occurred during the 2004/05 season when melting began in the openings at least 12 days after that below dense canopies.

Although additional information is required to establish robust conclusions, our results suggest that melt rates were generally higher below forest canopies than in openings when temperatures clearly exceeded $0^{\circ} \mathrm{C}$; however, the opposite trend was observed when temperatures only slightly exceeded $0^{\circ} \mathrm{C}$. This result may be related to the relative contributions of the different contributing fluxes of energy in generating snowmelt. Thus, if temperatures only slightly exceeded $0^{\circ} \mathrm{C}$, radiative fluxes played a key role in melting, and the shadow effect of the densest forest canopies acted to noticeably reduce the melting rates in the shielded areas (Davis and others, 1997; Sicart and others, 2004).

Previous studies report similar results, with lower melt rates beneath the forest canopy during rainfall events over the snowpack (Marks and others, 1998) and on days with high levels of incoming solar radiation or strong winds (Murray and Buttle, 2003; Talbot and others, 2006). Conversely, when temperature clearly exceeded $0^{\circ} \mathrm{C}$, sensible heat exchange and latent heat of evaporation were by far the most important drivers of melting. Thus, the shadow effect beneath the densest canopies would have played a relatively minor role in slowing melting in these areas. In addition, during warm spells the melt rates can be enhanced in areas close to trees because longwave radiation emitted by grey bodies (vegetation) is dependent on air temperature (Link and Marks, 1999). The greater accumulation of snow in the openings explained the fact that the snow-cover season was noticeably longer there than below forest canopies, regardless of the melt rates in the two settings.

A comparison of the measurements taken within the stand and those carried out at the open site showed similar results for both years. The accumulation of snow at the site unaffected by forest led to SWE values $28 \%$ and $40 \%$ higher than those measured below dense canopies, while melt rates were markedly higher than those observed within the stand, leading to earlier disappearance of the snowpack. The forest canopy also played an important role in controlling the degree of spatial variability in variation in the snowpack between the consecutive surveys. Thus, CVs of SWE variations were higher below dense canopies than in openings. As observed previously (Talbot and others, 2006; 
Winkler and Moore, 2006), heterogeneity in the horizontal and vertical structure of the forest explains the large variability found during accumulation periods in locations with dense canopies compared to the relatively homogeneous dynamics observed in the openings.

According to the above results, the maximum variability occurred at the beginning of the snow season and after long, dry spells when the canopy had no significant snow load. At times when the interception capacity was limited by the existence of a significant snow load, variability among different points located below dense canopy was much lower. During the melt period, variability between measurement points was lower, but a higher variability was found below the canopy than in openings. This finding reflects two factors: (i) differences in the distribution of shortwave radiation related to the complex structure of the canopy; and (ii) the distance between the measurement points and the nearest tree trunk, which controls the intensity of longwave radiation (Sicart and others, 2004). These results explain the observation that variability in SWE within openings was very low throughout the analysis period. Below the canopy, SWE was high at the beginning of the season but decreased after successive snowfall events, once accumulation had become established across the entire stand. Subsequently, variability in SWE below the densest canopies increased following accumulation events, when the canopy had a large interception capacity, and also throughout the melt periods.

\section{CONCLUSIONS}

The results obtained in this study show that in the analyzed stand, the maximum SWE beneath dense canopies was 50\% less than that in openings. The magnitude of the difference in snow accumulation was related to the amount of interception that occurred during particular snowfall events, although this was not the case throughout the accumulation season. The relation between SWE and SVF was highly linear, but the correlations showed a certain degree of variability between the analyzed years and throughout each snow season. A comparison of areas below dense canopies and openings showed that climatic conditions clearly affected the magnitude of the melt rates in the two environments. Sites unaffected by forest showed a similar pattern of SWE to the average trend of measured points in the stand; however, the snowpack in the site outside the forest melted faster than that at any of the points located within the stand. Finally, the snowpack exhibited a much higher degree of heterogeneity beneath dense canopies than in openings, and the CVs of SWE were particularly high at the beginning and end of the snow seasons.

These results confirm the importance of the dominant climatic conditions in explaining the effect of forest canopy on snowpack dynamics; however, further snow surveys in the coming years appear necessary to incorporate years with climatological conditions contrasting with those of the snow seasons described in the present study. These new surveys will generate additional information that can be used in performing a more robust statistical analysis to assess and specify the conclusions derived from the available data. A particular effort is needed to increase the number of surveys during the melt period, as a high variability related to particular climatic conditions has been detected under these conditions. Future research should also seek to measure/ simulate the snow energy balance at different sites within the analyzed stand to provide a more complete understanding of the role of the forest canopy on snow processes in the studied area.

\section{ACKNOWLEDGEMENTS}

This study was supported by the projects PROBASE: CGL2006-11619 and CANOA: CGL 2004-04919-C02-01, both financed by the Spanish Commission of Science and Technology and FEDER. Research undertaken by J.I. LópezMoreno was supported by a Postdoctoral Fellowship from the Spanish Ministry of Education, Culture and Sports. J. Latron benefited from a research contract (Juan de La Cierva Programme) funded by the Spanish Ministry of Education and Science. We thank colleagues and friends who helped during the measurement surveys, and the Parc National des Pyrénées and the Somport Nordic Ski Resort for the use of their facilities and permission to work in the study area.

\section{REFERENCES}

Bernier, P.Y. and R.H. Swanson. 1993. The influence of opening size on snow evaporation in the forests of the Alberta Foothills. Can. J. Forest Res., 23(2), 239-244.

Davis R. and 6 others. 1997. Variation of snow cover ablation in the boreal forest: a sensitivity study on the effects of conifer canopy. J. Geophys. Res. 102(D24), 29,389-29,396.

Hedstrom, N.R. and J.W. Pomeroy. 1998. Measurements and modelling of snow interception in the boreal forest. Hydrol. Process., 12(10-11), 1611-1625.

Hellstrom, R.A. 2000. Forest cover algorithms for estimating meteorological forcing in a numerical snow model. Hydrol. Process., 14(18), 3239-3256.

Keller, H.M. and T. Strobel. 1982. Water and nutrient discharge during snowmelt in subalpine areas. IAHS Publ. 138 (Symposium at Exeter 1982 - Hydrological Aspects of Alpine and High Mountain Areas), 331-341.

Koivusalo, H. and T. Kokkonen. 2002. Snow processes in a forest clearing and in a coniferous forest, J. Hydrol., 262(1-4), 145-164.

Link, T. and D. Marks. 1999. Distributed simulation of snowcover mass- and energy-balance in the boreal forest. Hydrol. Process., 13(14-15), 2439-2452.

López-Moreno, J.I. and J.M. García-Ruiz. 2004. Influence of snow accumulation and snowmelt on streamflow in the central Spanish Pyrenees. Hydrol. Sci. J., 49(5), 787-802.

López-Moreno, J.I. and J. Latron. 2008. Influence of canopy density on snow distribution in a temperate mountain range. Hydrol. Process., 22(1), 117-126.

López-Moreno, J.I. and M. Stähli. 2008. Statistical analysis of the snow cover variability in a subalpine watershed: assessing the role of topography and forest interactions. J. Hydrol., 348(3-4), 379-394.

Lundberg, A., Y. Nakai, H. Thunehed and S. Halldin. 2004. Snow accumulation in forests from ground and remote-sensing data. Hydrol. Process., 18(10), 1941-1955.

Marks, D., J. Kimball, D. Tingey and T. Link. 1998. The sensitivity of snowmelt processes to climate conditions and forest cover during rain-on-snow: a study of the 1996 Pacific Northwest flood. Hydrol. Process., 12(10-11), 1569-1587.

Mellander, P.-E., H. Laudon and K. Bishop. 2005. Modelling variability of snow depths and soil temperatures in Scots pine stands. Agric. Forest Meteorol., 133(1-4), 109-118.

Murray, C.D. and J.M. Buttle. 2003. Impacts of clearcut harvesting on snow accumulation and melt in a northern hardwood forest. J. Hydrol., 271(1-4), 197-212. 
Niu, G.-Y. and Z.-L. Yang. 2004. Effects of vegetation canopy processes on snow surface energy and mass balances. J. Geophys. Res., 109(D23), D23111. (10.1029/2004JD004884.)

Pomeroy, J.W. and D.M. Gray. 1995. Snow accumulation, relocation and management. Saskatoon, Sask., Environment Canada. National Hydrological Research Institute. (NHRI Sci. Rep. 7.)

Pomeroy, J.W., D.M. Gray, N.R. Hedstrom and J.R. Janowicz. 2002. Prediction of seasonal snow accumulation in cold climate forests. Hydrol. Process., 16(18), 3543-3558.

Sicart, J.E., R.L.H. Essery, J.W. Pomeroy, T. Link and D. Marks. 2004. A sensitivity study of daytime net radiation during snowmelt to forest canopy and atmospheric conditions. J. Hydromet., 5(5), 774-784.

Stähli, M. and D. Gustafsson. 2006. Long-term investigations of the snow cover in a subalpine semi-forested catchment. Hydrol. Process., 20(2), 411-428.

Talbot, J. and 6 others. 2006. Relating snow dynamics and balsam fir stand characteristics, Montmorency Forest, Quebec. Hydrol. Process., 20(5), 1187-1199.

Winkler, R.D. and R.D. Moore. 2006. Variability in snow accumulation patterns within forest stands on the interior plateau of British Columbia, Canada. Hydrol. Process., 20(17), 3683-3695. 